\title{
Preliminary Considerations of the Planning for Bohai Strait Subsea Tunnel
}

\author{
Xin Wang ${ }^{1, a^{*}}$, Xiangmei $\mathrm{Li}^{2, \mathrm{~b}}$, Peng Chen ${ }^{3, \mathrm{c}}$ and Haibo $\mathrm{Wu}^{4, \mathrm{~d}}$ \\ ${ }^{1}$ Yantai Vocational college, Yantai 264670, China \\ ${ }^{2}$ Yantai Productivity Promotion Center, Yantai 264003, China \\ ${ }^{3}$ Beijing CCCC Qiaoyu Science and Technology Co., Ltd., Beijing 100102, China \\ ${ }^{4}$ Shandong Shitong Highway Construction Co., Ltd., Zibo 256414, China

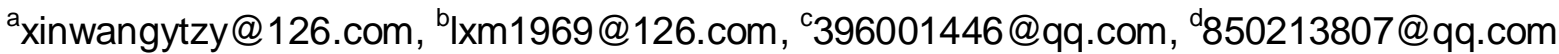

Keywords: Bohai strait; Subsea tunnel; Railway tunnel; Preliminary scheme

\begin{abstract}
Object: This paper is concentrated on the key problems of natural condition, line planning, landing sites, transportation mode, cross section and longitude section of Bohai strait subsea tunnel.

Methods: Bohai strait subsea tunnel is mainly researched by investigation of natural condition, comparison of analogous engineering, analysis of transportation mode, and the features of railway tunnel and highway tunnel.

Results and Conclusions: A scheme of full deep tunnel is suggested in Bohai strait. The proposal planar line of subsea tunnel starts from Laotieshan cape of Lvshun, ends at Donggang in Penglai, passing through Beihuangcheng island, Daqin island, Tuoji island, Beichangshan island, Nanchangshan island from north to South between the line section. The line is $114 \mathrm{~km}$ long. One shaft is set up separately for ventilation at Laotieshan cape, Beihuangcheng island, Beichangshan island and Donggang. Landing point in Shandong Peninsula is located at Donggang in Penglai and another landing point in Dalian is located at Laotieshan cape. Railways are used as transportation method and a piggy back system is proposed. To avoid all kinds of risks, the tunnel is about $80 \mathrm{~m}$ below the sea floor. The linear of longitudinal section is designed as $\mathrm{W}$ shape and the maximum longitudinal slope is set as $18 \%$, then the tunnel's length is about $125 \mathrm{~km}$. Cross section of the tunnel is a combination of double tubes and single tube, serving for the trains and other functions individually. The train speed is designed as $250 \mathrm{~km} / \mathrm{h}$.
\end{abstract}

\section{Introduction}

Bohai is the largest inner sea in China, its' outline is just as a letter of $\mathrm{C}$, from Liaodong Peninsula to Shandong Peninsula along the coastline. The construction of the Bohai strait subsea tunnel can relief the contradiction of Bohai ring region import and export transportation, North-South transportation and Collecting and distributing system of coastal ports, etc. It is of great significance to promote the comprehensive, coordinated and integrated development of the Bohai rim region and even the whole country. With the rapid development of modern economy, a new and higher requirements for marine transportation has been put forward. Although the current ship can be able to sail in the major oceans and accessing to all parts of the world smoothly, there are also a lot of limitations in maritime transportation, especially in short transportation of straits, more and more inevitable weakness are exposed. Compared with highway and railway transportation, timeliness of the maritime transportation is poorer in addition to its limited transportation volume. The distance between Yantai and Dalian is about $170 \mathrm{~km}$ in Bohai strait, 30h is demanded to complete a transport cycle. Considering the delayed time of loading and unloading, waiting in the port and in the ship, the actual time to complete a transport cycle is about $15 \mathrm{~d}[1,2]$. Meanwhile the maritime transportation is also affected greatly by climate and other factors, and cannot guarantee all-weather navigation. More importantly, there are also great risks and uncertainties with ship transportation. In order to solve these problems, a fixed passage must be constructed urgently to cross Bohai strait. 
To date, many channel tunnels have been built in the world, for example Kanmon tunnel built in Japan Kanmon straits in 1940s, the earliest channel tunnel in the world. In 1974, new Kanmon railway tunnel was built. Seikan tunnel built in Japan Tsugaru strait in 1988 is the longest subsea tunnel $(53.9 \mathrm{~km})$ so far in the world. The Channel Tunnel $(49.6 \mathrm{~km})$ has been excavated twice since Napoleonic Era (1800) but all halted, and was fully bored in 1993. Norway has built more than a dozen subsea tunnels successively. Recently, more than a dozen underwater tunnels have been built in China, for example Xiang'an subsea tunnel in Xiamen, Jiaozhou strait subsea tunnel in Qingdao, Shiziyang tunnel of high-speed railway and Hong Kong-Zhuhai-Macao cross sea passage. Cases statistics of subsea tunnels at home and abroad are listed in Table 1. Completions of these subsea tunnels have provided experiences and technologies support for Bohai strait tunnel.

Table 1 Case history of subsea tunnel project

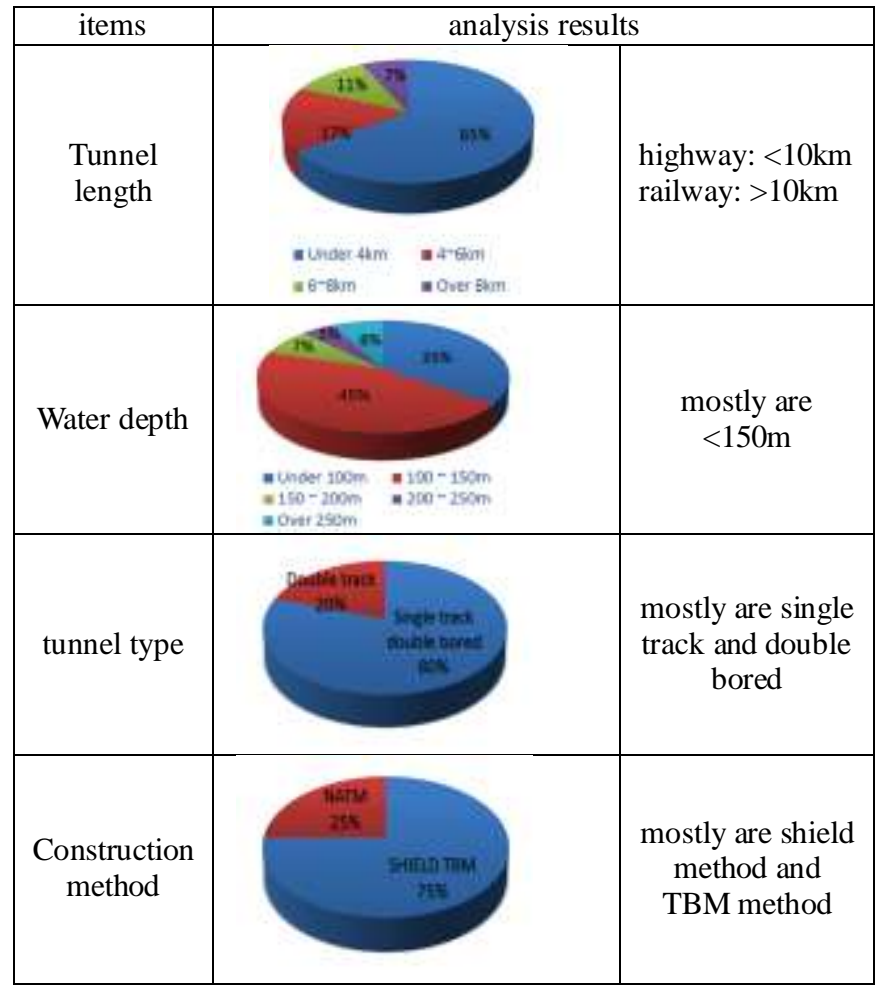

\section{Planar Lines Plan of Bohai Strait Subsea Tunnel}

Lines Plan. The width of Bohai strait is $106 \mathrm{~km}$, there are many islands distributed in the strait, and Miaodao Islands are located in the narrowest place of the strait. They are laid out just as a line from north to south, and their area is about $3 / 5$ of the strait's. The northest end is bout $42 \mathrm{~km}$ to Laotieshan cape, and the southest end is about $7 \mathrm{~km}$ to Penglai. There are all 32 islands, 66 reefs, 16 hidden reefs, 16 long beaches in Miaodao Islands. Their north-south length is $6.4 \mathrm{~km}$, east-west width is $30.8 \mathrm{~km}$, and distances between the islands are about $2 \sim 5 \mathrm{~km}$. In Miaodao Islands, Beihuangcheng island, Nanhuangcheng island, Daqin island, Gaoshan island, Daheishan island, Beichangchangshan island, Nanchangshan island are the larger islands, among these islands, Nanchangshan island is the largest island of $12.8 \mathrm{~km}[2,7,8]$. The average water depth is $25 \mathrm{~m}$ in Bohai strait. Depth contour of $5 \mathrm{~m}$ is ditributed in the south islands' coast, and depth contour of $10 \mathrm{~m}$ is distributed in the north islands' coast. Erosion depression is general $50 \mathrm{~m}$ deep, and the deepest waterway is $86 \mathrm{~m}$ in Laotieshan waterway. The above islands and waterways are shown as Fig. 1[8]. 


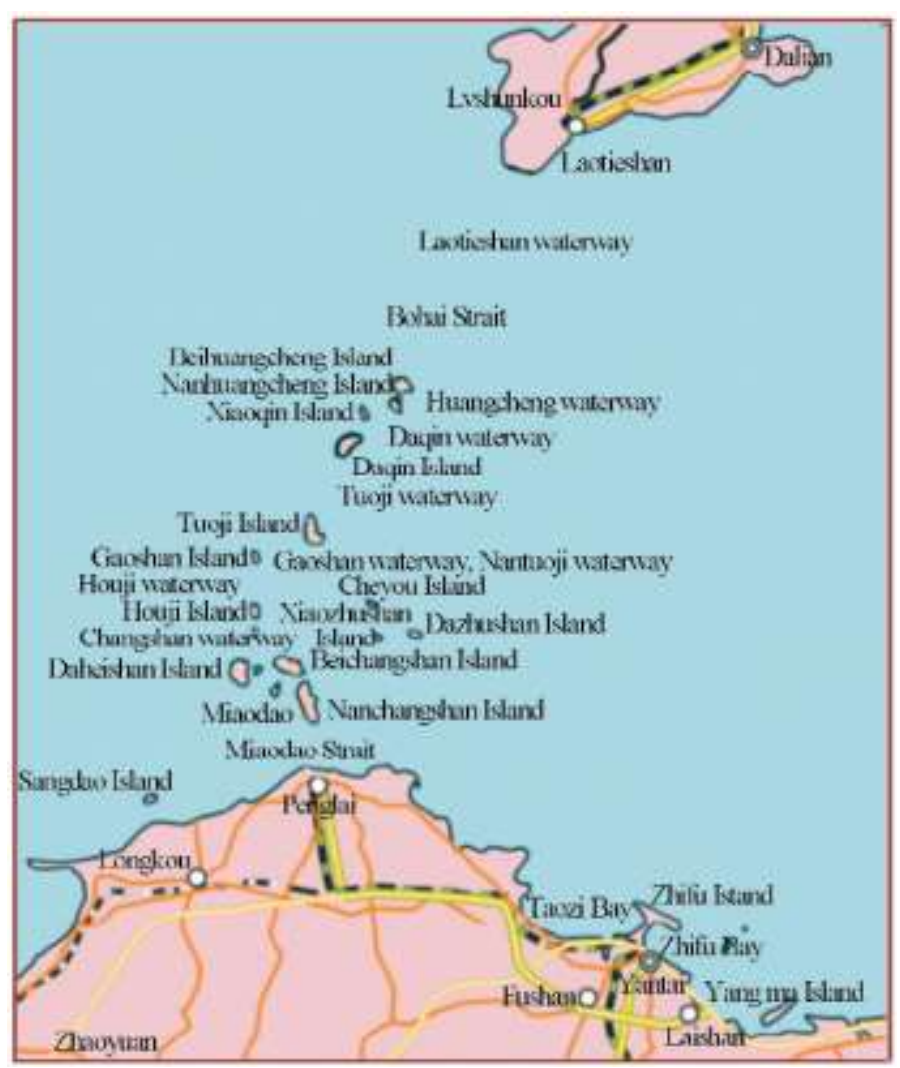

Figure 1. Distribution of main islands

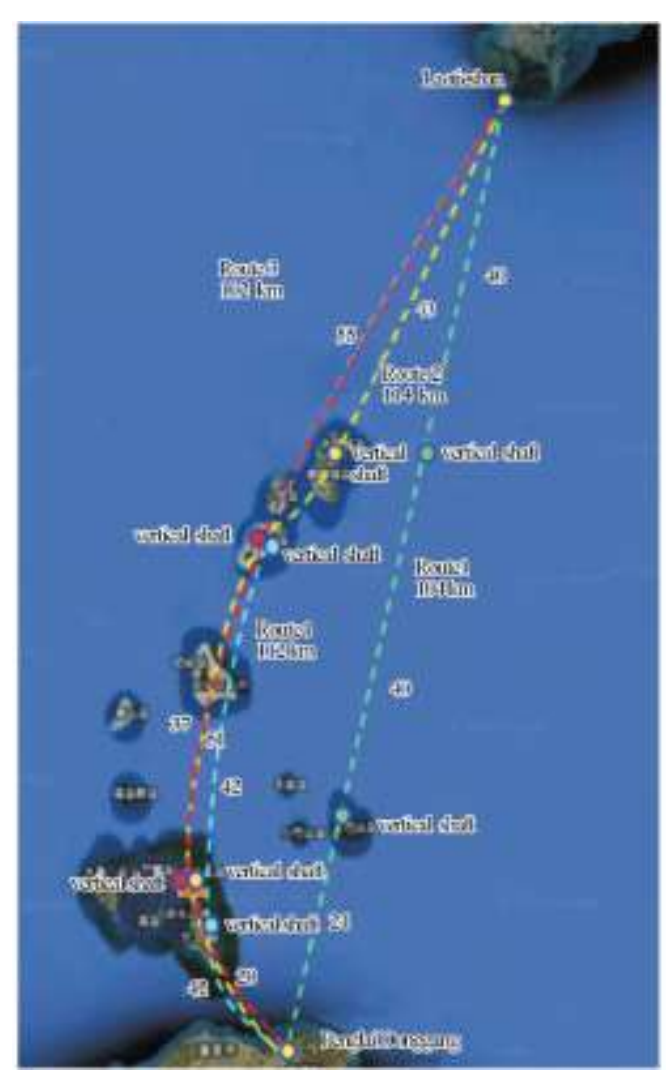

Figure 2. Several contrast of the and waterways

According to the conditions of width, water depth, terrain, geology, earthquake, transportation in Bohai strait, the lines plan are designed and compared[9]. Four passage lines schemes are proposed, shown as Fig. 2.

The terrain and geology of the four lines are basically alike, a little differences are the passing islands and the sea width. If water depth is considered deep groove must be avoided as far as possible, then line 2, line 3 and line 4 are slightly dominant. Meanwhile if we think over technology requirement of shaft settlement, economy feasibility and construction site, line 2 is obviously dominant. Line 2 avoids the deepest groove of Laotieshan waterway because it passes the waterway at the upstream of "V" shape groove. It is about $80 \mathrm{~m}$ deep. Then line 2 passes the main islands subsequently and the sea area is the narrowest. Line 3 and line 4 also passes partial islands and avoids the deepest groove in Laotieshan waterway, but its sea area is about $55 \mathrm{~km}$ wide passing Laotieshan waterway, the shaft interval is wider, its scheme feasibility is poor.

In summary, for civil engineering, line 2 is the optimal scheme of Bohai way subsea tunnel. Because its passing sea area is the shortest, and the longest sea area of $43 \mathrm{~km}$ can meet the shaft interval of the tunnel. Its water is shallower relatively and keeps away from several deep groove in seabed. In addition people's livelihood and economy development in the islands are considered synthetically in line 2. The line connecting Penglai to Lvshun, can take full advantage of the passing islands and can decrease the engineering difficult and construction risks to the maximum extent by means of adjusting the line's location and trend. The scheme can also improve the train's running conditions. At the same time, stratum of line 2 is stable relatively, it is located in two group faults of NNE, and is parallel with the faults. The line is about $40 \mathrm{~km}$ from Tanlu fault zone and only passes through two larger faults of NW. The full tunnel scheme passes Laotieshan waterway from Lvshun, passing through Beihuangcheng island, Daqin island, Tuoji island, Beichangshan island and Nanchangshan island successively, and landed at Donggang in Penglai at last. The tunnel is about $125 \mathrm{~km}$ long. 
Landing Sites. The landing site of Dalian is set at Laotieshan cape of Lvshun, and the site has been reserved in city planning(Fig. 3).

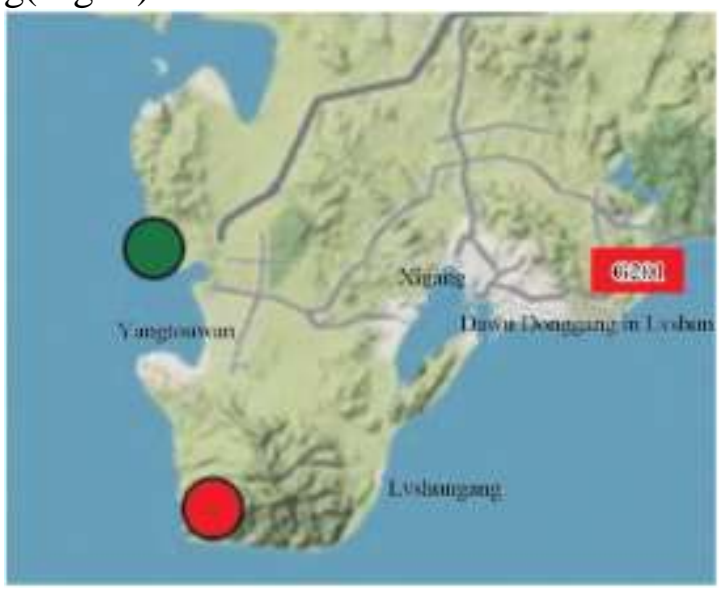

Figure 3. Location plan of landing site in Dalian

There are four landing sites in Yantai Penglai which are Fenghuotai, East of Penglai, Donggang and Heishizui from west to east[10]. Shown as Fig. 4. Synthetically analysis of ecology environment, city planning and coast line, Donggang is the optimal landing site in Penglai.

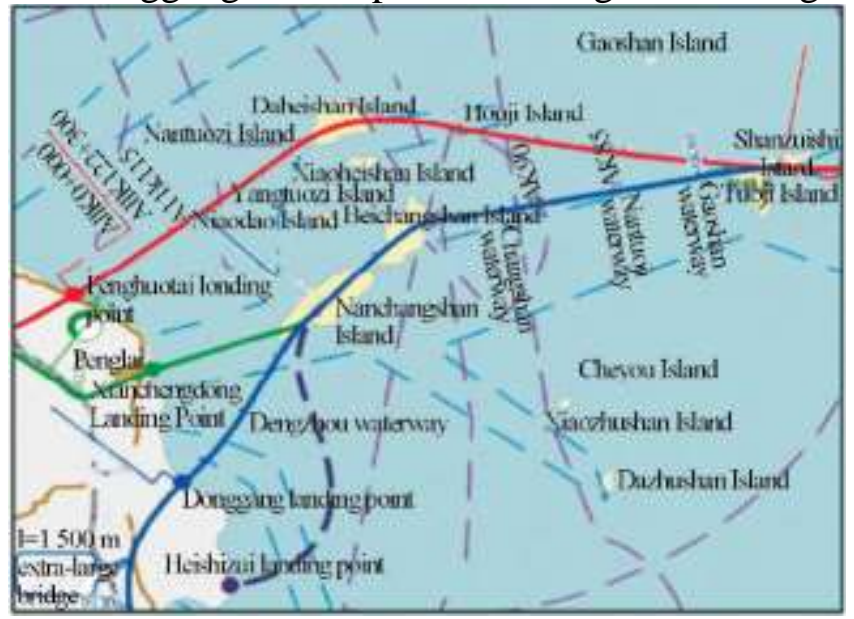

Figure 4. Location plan of landing site in Penglai

\section{Transportation Mode of Bohai Strait Subsea Tunnel}

Bohai strait tunnel must meet the demands of railway transport and highway transport. For the problem of ventilation, length of underwater highway tunnels is far beneath that of underwater railway tunnels. If the automobiles directly drive in the tunnel, cross section must be enlarged and the ventilation system should be installed. Meanwhile several artificial islands must be built up in the sea to construct ventilating shafts, such as Tokyo Strait subsea highway tunnel( $9.5 \mathrm{~km}$ long). It is inevitably to increase the difficulty of construction and will lead to substantial increase in project cost and ventilation cost. Functional facilities such as lighting, monitor and disaster prevention will also increase operating costs. Drivers are prone to feeling of tension and fatigue when the automobiles are running continuously in the super long highway tunnel. The accident rate is much higher than that of railway tunnel, and the longer the tunnel, the worse the security.

Consequently, railway transport should be used in Bohai strait tunnel. High speed trains and shuttle trains can be run at the same time in the tunnel and automobiles can take the shuttle train through the tunnel as piggyback systems. It is consistent with the transport way of the world's major submarine tunnels. In accordance with the experience of domestic and foreign high-speed railway tunnels, The train speed of $250 \mathrm{~km} / \mathrm{h}$ is proposed. 


\section{Longitudinal Section and Cross Section of Bohai Strait Tunnel}

\section{Longitudinal Section of the Tunnel. ( 1 ) Considering of longitudinal gradient}

The problem of longitudinal gradient should be considered according to the engineering construction feasibility, construction risks, the tunnel operating and the demands of disaster prevention and rescue. Considering the conditions of topography, geology and water depth of both sides of the strait and the seabed, four gradient schemes are proposed as 9\%o, $12 \%$, 18\%o and $25 \%$. The scheme of $9 \%$ will lead longer tunnel, which is prone to cost more money. The length of $25 \%$ scheme is shorter $3.5 \mathrm{~km}$ and $2.0 \mathrm{~km}$ than that of $12 \%$ and $25 \%$ respectively. Its effect is not only unobvious to shorten the tunnel but also deterioration of operating conditions and disaster mitigation conditions, meanwhile it will lead to great increasing of operating cost. So the schemes of $9 \%$ and $25 \%$ are both undesirable. The tunnel length difference between $12 \%$ and $18 \%$ o is only about $2.0 \mathrm{~km}$, gradient of $18 \%$ is suggested to shorten the tunnel's length.

( 2 ) The minimum buried depth

Minimum buried depth of subsea tunneling is depended on the maximum water pressure, construction safety and stability of seabed and so on. If the buried depth is too thin, the tunnel lining will bear more high water pressure, its surrounding rock condition and tunneling safety are relatively poorer. If the buried depth is too thick, the tunneling is relatively safe, but the tunnel is too long and the tunneling cost is too high. The longitudinal gradient design becomes difficulty.

In accordance with preliminary geological conditions, In Bohai seabed, the upper part is quaternary deep-water sediment, the lower part are basalt, quartzite and granite. But hydrological conditions are poor in the strait and the seabed evolution is unknown. For the tunnel's safety the subsea tunnel should be set in the deeper rock stratum. meanwhile the rock surrounding the tunnel should have good water isolation which can decrease work pressure of the TBM. It is convenient to select good location to change the cutting tools, fix the machine and dock the two machines beneath the seabed. It can meet the demand of long tunneling of one TBM. Synthetically, the buried depth of about $80 \mathrm{~m}$ is proposed for Bohai strait tunnel.

(3) Longitudinal section choice. The stratum of the tunnel is constituted by quartzite, granite and basalt, which have good self stability, arching effect and good water separation. This stratum is favor to reduce the water pressure behind the lining. Vertical distance is about $160 \mathrm{~m}$ from the sea level to the tunnel vault of the deepest location and the rock cover thickness at this site is about $80 \mathrm{~m}$. According to the cover thickness length of the tunnel is about $125 \mathrm{~km}$. To reduce the water pressure applying on the lining during the tunnel's operation and the other disease problems. In favor of drainage of the tunnel and decreasing drainage cost, longitudinal section of the subsea tunnel is designed as W shape. The longitudinal section of Bohai strait tunnel is shown as Fig. 7.

(4) Shaft setting. The factors of tunneling, operating ventilation, the maximum tunneling distance of a TBM and construction site should be considered to design the shafts. Four shafts are set at Laotieshan cape of Lvshun, Beishuangcheng island, Beichangshan island and Donggang of Penglai respectively which is to service the tunnel construction. In consideration of other functions, a elevator passage can be added into the shaft to service the passengers when the ventilation shaft is designed at Beichangshan island. Meanwhile two shafts can be set at Daqin island and Tuoji island respectively to add working face of tunneling. It can slow down construction pressure of shaft at Beihuangcheng island and can be a passenger access or drainage path of the tunnel at the same time. 


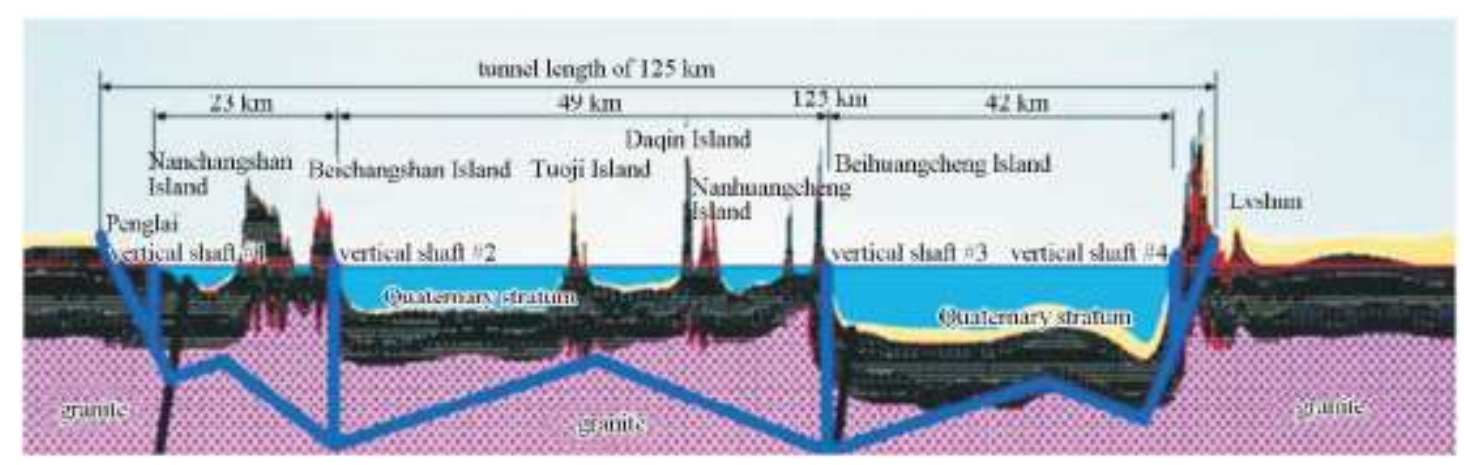

Figure 5. Longitudinal profile view of Bohai strait subsea tunnel

Cross Section of the Tunnel. Generally schemes of double track railway tunnel are as the following four cross section: double bored and single track, single bored and double track, single bored and double track and partition wall, double bored and single track and service bored. According to the scheme of double bored and single track, the train runs unidirectionally in one hole, the train's running is high safe. People are evacuated into another tunnel without accident by means of lateral channel, but escape space is small. To this scheme, abilities of disaster prevention and evacuation are strong, but it cannot predict advanced geological conditions and reinforce the adverse geological body and the construction risks are relatively great. For the scheme of single bored and double track, bi-directional trains runs synchronously in one hole and its risks are high. When one train meets accidents, secondary disaster may happen on another train and the abilities of disaster prevention and evacuation are weak. The cross section of the tunnel is larger and no service tunnel can be used to predict advanced geological conditions and reinforce the adverse geological body. So its construction difficult and risks are greatest. For the scheme of single bored and double track and partition wall, when the accident happens, passengers can escape into the other hole without disaster through lateral channel and this scheme have strong evacuation ability. The cross section is larger and its construction difficult and risks are relatively great. For the scheme of double bored and single track and service bored, it is be beneficial to construction safety and tunnel longitudinal ventilation with jet blower in construction. It is of less operational risks and strong ability of disaster prevention and rescue. The service hole can be bored ahead to explore the stratum condition along the tunnel line and can also be as the sites of refuge and rescue of subsequent construction of the main tunnel.

Above all the scheme of double bored and single track and service bored is recommended to be as the cross section of Bohai strait tunnel.

The cross section of the tunnel is shown as Fig. 8. The tunnel system is consisted of two main tunnels and one service tunnel. The distance between the main tunnel and the service tunnel is $30 \mathrm{~m}$. One transverse channel is set up along the tunnel every $500 \mathrm{~m}$ to connect the two main tunnels and the service tunnel. One pressure-relief channel is set up along the tunnel every $500 \mathrm{~m}$ interval with the transverse channel to connect the two main tunnels to relieve the pressure and slow down the air resistance of the high speed train. Three dimension effect of the tunnel is shown as Fig. 9. According to cross section of high speed railway tunnel in China, inner clearance area of $66 \mathrm{~m} 2$ can meet the demand of $200 \mathrm{~km} / \mathrm{h} \sim 250 \mathrm{~km} / \mathrm{h}$ of the passenger trains. Analysis on cross section of the Channel Tunnel, the preliminary geometry sizes of Bohai strait tunnel are designed as the follows: external diameter of the main tunnel is $11.3 \mathrm{~m}$, external diameter of the service tunnel is $9.5 \mathrm{~m}$, external diameter of the transverse channel is $4.7 \mathrm{~m}$, external diameter of the pressure-relief channel is $4.1 \mathrm{~m}$. Composite lining is utilized in the tunnel. For the main tunnels, primary support is $30 \mathrm{~cm}$ and secondary support is $50 \mathrm{~cm}$; For the service tunnels, primary support is $30 \mathrm{~cm}$ and secondary support is $45 \mathrm{~cm}$; For the transverse channel and the pressure-relief channel, primary support is $30 \mathrm{~cm}$ and secondary support is $40 \mathrm{~cm}$. 


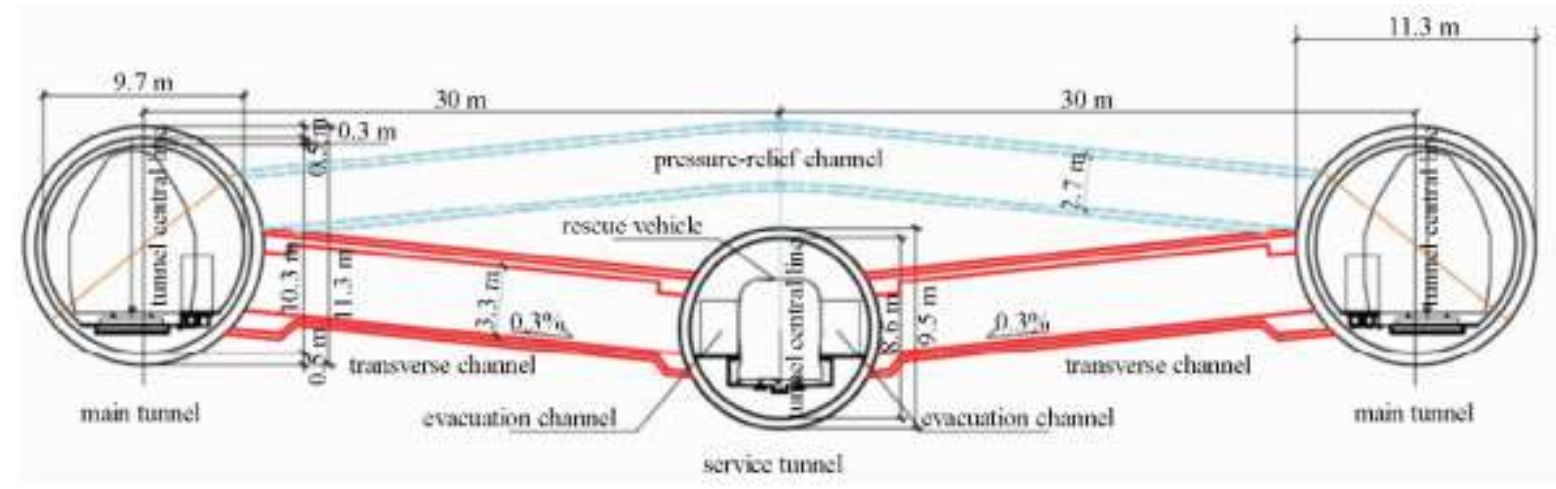

Figure 6. Cross section view of Bohai strait subsea tunnel

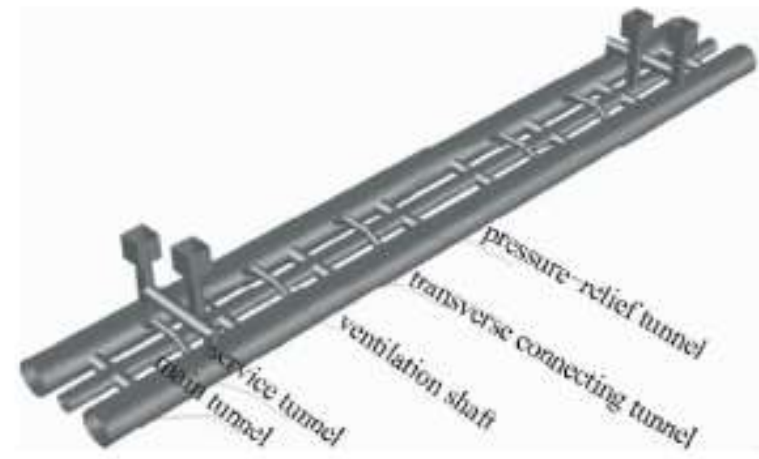

Figure 7. Three dimensional view of Bohai strait subsea tunnel

\section{Conclusions and Advises}

(1) Surveying the area, population, distances and water ways along the cross sea passage, and considering the requirements and the advises on city planning and transport development of Lvshun, Changdao and Penglai, full deep tunnel scheme is suggested in Bohai strait. The proposal planar line of subsea tunnel starts from Laotieshan cape of Lvshun, ends at Donggang in Penglai, passing through Beihuangcheng island, Daqin island, Tuoji island, Beichangshan island, Nanchangshan island from north to South between the line section. The line is $114 \mathrm{~km}$ long. One shaft is set up separately for ventilation at Laotieshan cape, Beihuangcheng island, Beichangshan island and Donggang. To avoid all kinds of risks, the tunnel is about $80 \mathrm{~m}$ below the sea floor. The linear of longitudinal section is designed as $\mathrm{W}$ shape and the maximum longitudinal slope is set as $18 \%$, then the tunnel's length is about $125 \mathrm{~km}$. Railways are used as transportation method and cars are transported within the train crossing the sea as a piggy back system. Landing point in Shandong Peninsula is located at Donggang in Penglai and another landing point in Dalian is located at Laotieshan cape. Cross section of the tunnel is a combination of double tubes and single tube, serving for the trains and other functions individually. The train speed is designed as $250 \mathrm{~km} / \mathrm{h}$.

(2) When Bohai strait subsea tunnel is designed and constructed, the principle of security, reliability, applicability, economy is must be held, and the order is not allowed to be changed.

(3) Bohai strait subsea tunnel is a high risk under water engineering, and there are many high risk resources. Safety and risk analysis must be considered seriously in the processes of planning, design, construction and operation.

(4) Due to difficulties and great costs in marine geological exploration especially the deep groove exploration, the risks of leakage survey and information distortion are greater, advanced geological prediction of the tunneling should be enhanced.

(5) Controlling of water intruding and water gushing of subsea tunnel is the key to engineering design and construction. The surrounding rock of seabed is more likely to be softened and permeable, shoals and strong weathering sections, weathering deep groove under seabed are also prone to 
permeation and inrushing. These sections are mostly connected to the sea water directly, and are of great construction difficulties and risks, and should be paid more attention. For example, serious water inrush accidents have been happened in the construction of Seikan Tunnel and Great Belt Strait Tunnel, and These are all profound lessons for us.

\section{Acknowledgements}

This paper is sponsored by the Natural Science Foundation of China (No.51478213,51278237).

\section{References}

[1] L.Q. Wei, X.H. Liu, L.Z. Liu, et al: Study on Several important issues of Bohai strait cross-sea channel(Economic Science Press, China, 2007), p.54-122.(in Chinese)

[2] M.S. Wang, K.Z. Song: Journal of Beijing Jiaotong University, Vol. 37 (2013) No.1, p.1-10.(in Chinese)

[3] M.S. Wang: Chinese Journal of Rock Mechanics and Engineering, Vol. 27 (2008) No.11, p.2161-2172.(in Chinese)

[4] H. Tuneyoshi: Proceedings of the word tunnel congress'99 - Challenges for the 21st Century (Norway, May, 1999). p.543-554.

[5] R.K. Thomas (Translated by Y. Wang): World Tunnel, (1997) No.5, p.36-41.

[6] Z.S. Tan, M.S. Wang, S.X. Luo: China Engineering Science, Vol. 11 (2009) No.7, p.39-44.(in Chinese)

[7] Z.S. Tan, M.S. Wang, M. Zhang: Chinese Journal of Geotechnical Engineering, Vol. 23 (2001) No.2, p.139-143.(in Chinese)

[8] Z.S. Tan, Y.S. Wu, F. Wan: China Engineering Science, Vol. 15 (2013) No.12, p.32-38.(in Chinese)

[9] M.S. Wang: China Engineering Science , Vol. 15 (2013) Np.12, p.4-9.(in Chinese) 